\title{
Original
}

\section{Quantitative Analysis Using Overlap Images with Technetium-99m Pyrophosphate Thallium-201 Dual-isotope SPECT to Evaluate Microvascular Reperfusion Injury Following Successful Coronary Intervention in Patients with Acute Myocardial Infarction}

\author{
Hideki Nishimura ${ }^{1)}$, Yasushi Akutsu ${ }^{1}$, Yuji Hamazaki ${ }^{1}$, \\ Masayuki SAKURAi ${ }^{1)}$, Meiei Shigemitsu ${ }^{11}$, Yusuke Kodama ${ }^{1)}$, \\ Hui-Ling $\mathrm{LI}^{1}{ }^{1}$, Takeshi Kondo', Hitoshi EzUMI ${ }^{1)}$, \\ Hideyuki YamanaKa ${ }^{2)}$, Akira ShINOZUKA ${ }^{1)^{\prime}}$ and Takashi KATAGIRI ${ }^{1)}$
}

\begin{abstract}
We evaluated the extent of reperfusion injury (RI) following successful coronary intervention quantitatively and non-invasively using technetium-99m pyrophosphate (Tc-PYP)/thallium-201 dual-isotope single photon emission computed tomography (SPECT). Tc-PYP/thallium-201 SPECT was performed 48 hours after coronary intervention in 67 patients $(62.6 \pm 12.1 \mathrm{yr})$ who had undergone successful coronary intervention (TIMI grade 3 ) in the infarct-affected left anterior descending coronary artery within 6 hours after acute anteroseptal myocardial infarction. The infarct-affected region, which was defined quantitatively by a $>55 \%$ uptake of Tc-PYP, was considered as showing RI if the recovery of myocardial perfusion was defined quantitatively by $<60 \%$ uptake of thallium-201. Left ventriculography was performed immediately after intervention and at the 6-month follow-up. These clinical parameters were compared between patients with and without RI. RI was presented in 32 of the 67 patients. Electrocardiographic ST-segment elevations did not return to normal immediately after intervention in the patients with RI as compared to the patients without RI $(62.5 \%$ of 20 patients versus $25.7 \%$ of $9, P<0.01$ ). The patients with RI had larger infarcts (Unit/L) $(5490 \pm 3002$ versus $2506 \pm 2074, P<0.0001)$, more severe left ventricular function $(43 \pm 11.8 \%$ versus $50.2 \pm 10.2 \%, P<0.05)$, and larger end-diastolic left ventricular dilatation at the 6-month follow-up $(\mathrm{mL} / \mathrm{m} 2)(101 \pm 27.2$ versus $85.2 \pm 24.1, P<0.05)$ than the patients without $\mathrm{RI}$. This study therefore demonstrates that RI occurring soon after successful coronary intervention following acute myocardial infarction can be detected quantitatively by overlap SPECT images of Tc-PYP/thallium-201.
\end{abstract}

Key words : technetium-99m pyrophosphate and thallium-201 dual-isotope SPECT, coronary intervention, acute myocardial infarction, reperfusion injury, TIMI grade 3 .

\footnotetext{
1) Third Department of Internal Medicine, Showa University School of Medicine, 1-5-8, Hatanodai, Shinagawa-ku, Tokyo 142-8666, Japan.

2) Department of Radiology, Showa University School of Medicine.
} 


\section{Introduction}

Early reperfusion therapy after acute myocardial infarction leads to restoration of infarct-related coronary blood flow, and as a result, reperfusion of the infarct-related myocardium ${ }^{1)}$. The Thrombolysis in Myocardial Infarction (TIMI) flow grade on angiography is used to estimate the success of reperfusion therapy ${ }^{2,3)}$, and is directly related to the efficacy of myocardial salvage. However, complete restoration of coronary blood flow does not always mean the complete salvage of infarct-related myocardium because obstruction of coronary flow in damaged distal microvessels may persist despite successful coronary intervention ${ }^{4)}$. It is important for the cardiologist to detect any transient microvascular reperfusion injury after successful coronary intervention, as this reperfusion injury can adversely affect the prognosis ${ }^{5,6)}$. Persistent ST-segment elevation or re-elevation shortly after successful coronary angioplasty correlates well with impaired myocardial reperfusion at the microcirculatory level ${ }^{7)}$. Recently, microvessel dysfunction following a successful coronary intervention was assessed non-invasively using contrast-enhanced magnetic resonance imaging $(\mathrm{MRI})^{6)}$ or myocardial contrast echocardiography ${ }^{5)}$. However, these procedures do not provide a quantitative evaluation of the microcirculatory flow, and do not detect the infarct-related area or infarct size accurately.

Thallium-201 myocardial perfusion single photon emission computed tomography (SPECT) has been used to quantitatively assess not only the viability of infarct-related myocardium before coronary angioplasty ${ }^{8)}$, but also microvessel dysfunction following successful coronary intervention ${ }^{9)}$. In addition, technetium- $99 \mathrm{~m}$ pyrophosphate SPECT was introduced to quantify infarct size and/or the spatial extent of non-viable myocardium ${ }^{10,11}$. Recently, overlap images of simultaneous dual-isotope SPECT using thallium-201 and technetium-99m detected the location of acute myocardial infarction with a high degree of accuracy $^{12)}$, and distinguished the myocardial scar from stunned, hibernating or viable myocardium $^{13)}$.

The aim of this study was to evaluate microvascular reperfusion injury quantitatively and non-invasively using technetium-99m pyrophosphate/thallium-201 dual-isotope SPECT early after successful coronary intervention.

\section{Methods}

\section{Patient population}

A total of 67 patients with first acute anteroseptal myocardial infarction were recruited to this study. Acute myocardial infarction was diagnosed by persistent chest pain lasting more than 30 minutes, ST-segment elevations of more than $2 \mathrm{~mm}$ in at least 2 contiguous leads on ECG, and a typical elevation of serum creatine kinase. The patients were selected for primary percutaneous transluminal coronary intervention if they fulfilled the following conditions: onset-to-admission interval of $\leq 6$ hours, and a significant stenosis of the left anterior descending coronary artery. The position of coronary artery stenosis was referenced according to the American Heart Association classification for coronary angiography ${ }^{14}$, and the diameter of stenotic coronary artery was measured quantitatively using a computer system. The collateral circulation was evaluated on coronary angiographic findings according to Rentrop's classification ${ }^{15)}$, and the presence of collaterals was considered to be either grade 2 or 3. 


\section{Cardiac catheterization and coronary intervention}

The patients underwent successful coronary intervention with Thrombolysis In Myocardial Infarction (TIMI) trial grade 3 flow re-established ${ }^{2)}$, and the infarct-related coronary artery had a residual diameter stenosis of less than $50 \%$ after coronary intervention. Coronary intervention was performed with a combination of devices: balloon angioplasty, stenting, thrombolysis, and aspiration systems. Arterial diameter at the angioplasty site was measured quantitatively on the end-diastolic frames, and two orthogonal projections were used to compute the minimal lumen diameter and the percent diameter stenosis. Left ventriculography was performed immediately following coronary intervention to assess left ventricular dilatation and function. The end-diastolic volume index (LVEDVi) $(\mathrm{mL} / \mathrm{m} 2)$, the end-systolic volume index (LVESVi) $(\mathrm{mL} / \mathrm{m} 2)$, and the left ventricular ejection fraction (LVEF) (\%) were measured according to the area-length method ${ }^{16)}$ on the $30^{\circ}$ right anterior oblique projection of the left ventriculography, and the follow-up left ventriculography was performed with coronary angiography approximately 6 months after coronary intervention. Written informed consent was obtained from all patients.

\section{Tc-pyrophosphate/thallium-201 dual-isotope SPECT imaging and analysis}

Each patient underwent Tc-pyrophosphate/thallium-201 dual-isotope SPECT 48 hours after successful coronary intervention. Twenty $\mathrm{mCi}(740 \mathrm{MBq})$ of $\mathrm{Tc}$-pyrophosphate was injected intravenously, and then $3 \mathrm{mCi}(111 \mathrm{MBq})$ of thallium-201 was injected 2 hours later. Dual-isotope SPECT was started 5 minutes after the injection of thallium-201. SPECT was performed with a rotating large-field-of-view gamma camera with low-energy, high-resolution, parallel-hole collimetor (Prizm 2000XP, Picker Co., Philadelphia, pA, USA.) and interfaced with an Odyssey computer (Picker Co.). Data were acquired in a $64 \times 64$ matrix involving 32 step-and-shoot projections over $180^{\circ}$ at $40 \mathrm{sec}$ per projection, beginning $45^{\circ}$ in the right anterior oblique projection. Two energy windows were selected for dual-isotope SPECT imaging using the two tracers: the 140-keV photopeak of Tc with a $20 \%$ window and the $75-\mathrm{keV}$ photopeak of thallium-201 with a $20 \%$ window. No downscatter correction was performed. The reconstructed transaxial slices were then reoriented into the vertical long, horizontal long, and short axes. After determining the axis of the left ventricle by the thallium-201 short axis image, scintigrams of Tc-pyrophosphate and thallium-201 simultaneously obtained from the identical slice of the short axial image were superimposed for analysis ${ }^{12)}$; these images were analyzed by two independent observers unaware of the clinical courses. From these short axis images, a polar map was obtained in each radioisotope. The short-axis images of the left ventricle were divided into the apical, middle, and basal slice levels using a polar map, with the last two levels further divided into 8 additional areas, thereby yielding a total of 17 regions. The infarct-related region was considered to be present if the percentage uptake of Tc-pyrophosphate radioactive counts in any one of the mapped regions was more than $55 \%$. In all of the infarct-related regions, the mean percentage uptakes of Tc-pyrophosphate and thallium-201 were calculated quantitatively in each patient. The reperfusion injury (RI) was considered to be present if the percentage uptake of thallium-201 radioactive counts in all of the infarct-related regions was less than $60 \%$ (Fig. 1). 


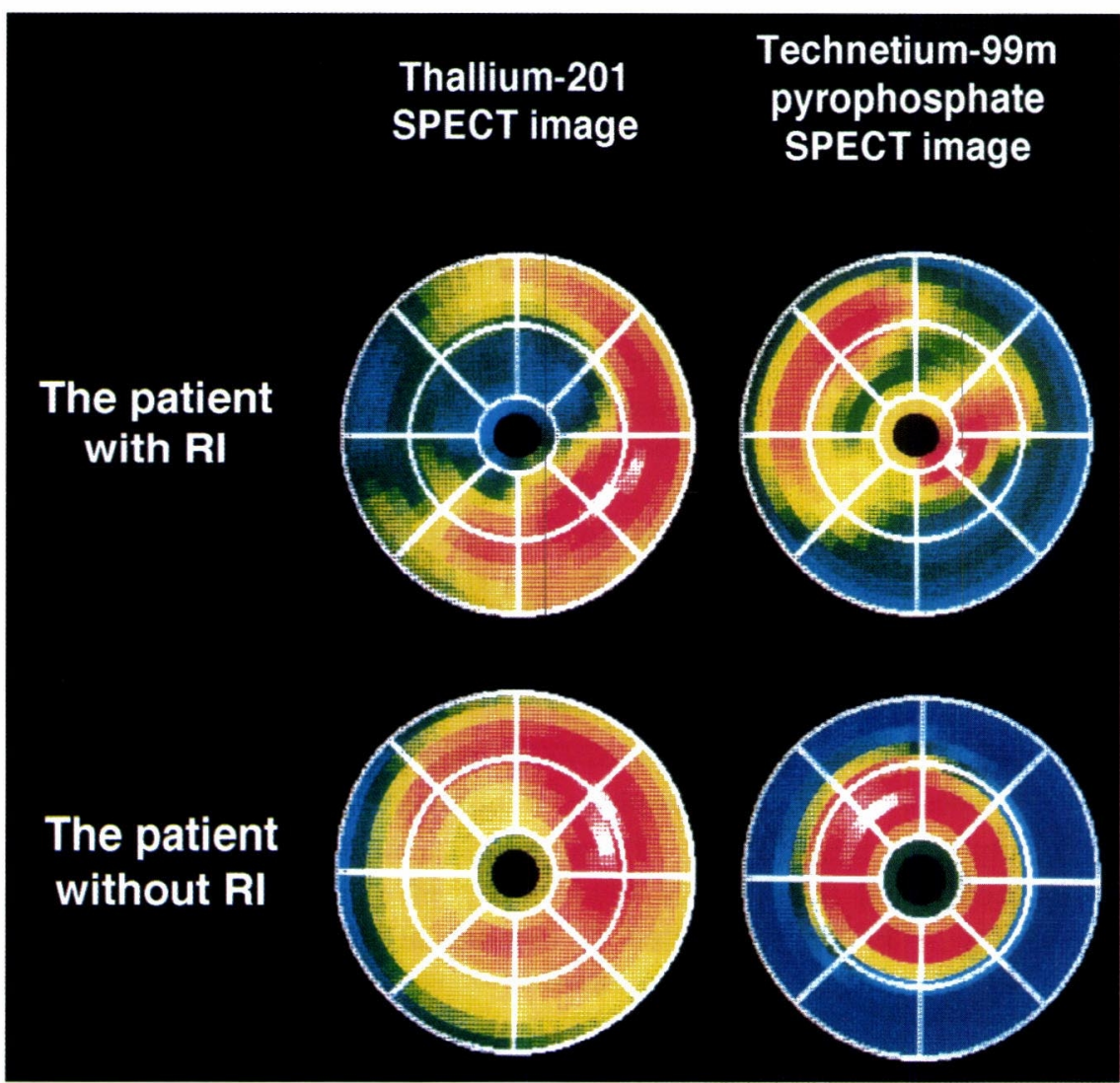

Fig. 1. Overlap images with technetium-99m pyrophosphate/thallium-201 dual-isotope SPECT Typical SPECT images from patients with reperfusion injury (RI) are shown in the upper side of the figure. The myocardial perfusion flow was reduced in the infarct-related regions with high \% uptake of technetium- $99 \mathrm{~m}$ pyrophosphate despite successful coronary intervention. Typical SPECT images from patients without RI are shown in the lower side of the figure. The myocardial perfusion flow recovered in the infarct-related regions with high \% uptake of technetium- $99 \mathrm{~m}$ pyrophosphate after successful coronary intervention.

\section{Statistical analysis}

Data are presented as the mean \pm SD. Comparisons of continuous variables and categorical variables between two groups were calculated by the Student's $t$ test and chi-square test, respectively. A $P$ value $<0.05$ was considered significant.

\section{Results}

\section{Dual isotope SPECT imaging}

RI was presented in 32 patients with acute myocardial infarction after reperfusion, and was absent in 35 patients. The peak creatine kinase and iso-enzyme levels were higher in the patients with RI than in the patients without RI $(5490 \pm 3002$ Unit/L versus $2506 \pm$ 2074 Unit/L, $P<0.0001$ for the creatine kinase, and $604 \pm 372 \mathrm{Unit} / \mathrm{L}$ versus $322 \pm 321 \mathrm{Unit} / \mathrm{L}$, $P<0.0001$ for the creatine kinase iso-enzyme). Similarly, the number of infarct-related regions tended to be higher in the patients with RI than in the patients without RI ( 8.1 
Table 1. Patient characteristics

\begin{tabular}{lccc}
\hline & 32 patients with RI & 35 patients without RI & p value \\
\hline Age & $64.5 \pm 10.6$ & $60.9 \pm 13.1$ & $p=$ N.S. \\
Male & $26(81.2 \%)$ & $30(85.7 \%)$ & $p=$ N.S. \\
Hypertension & $26(81.2 \%)$ & $28(80.0 \%)$ & $p=$ N.S. \\
Diabetes mellitus & $12(37.5 \%)$ & $5(14.2 \%)$ & $p=0.0277$ \\
Hyperlipidemia & $13(40.6 \%)$ & $20(57.1 \%)$ & $p=$ N.S. \\
Smoking & $25(78.1 \%)$ & $19(54.2 \%)$ & $p=0.0380$ \\
Obesity (BMI $>25)$ & $7(21.8 \%)$ & $9(25.7 \%)$ & $p=$ N.S. \\
History of angina & $16(50 \%)$ & $18(51.4 \%)$ & $p=$ N.S. \\
Time course to intervention from the onset & $4.0 \pm 2.1$ & $4.1 \pm 2.6$ & $p=$ N.S. \\
Multivessel disease & $9(28.2 \%)$ & $9(25.8 \%)$ & $p=$ N.S. \\
Collateral circulation & $12(37.5)$ & $11(31.4)$ & $p=$ N.S. \\
\hline
\end{tabular}

RI : reperfusion injury, BMI : body mass index, $p=$ N.S.: no significance. All data are expressed as the mean \pm 1 standard deviation.

\pm 2.5 regions versus $7.0 \pm 3.1$ regions, $P=$ N.S.). However, the mean \% uptake of thallium-201 in the infarct-related regions was significantly lower in the patients with RI than the patients without RI $(51.4 \pm 5.3 \%$ versus $70.3 \pm 10.0 \%, P<0.0001)$, although there was no significant difference in the mean \% uptake of Tc-pyrophosphate in the infarctrelated regions between the two groups $(72.6 \pm 5.6 \%$ versus $75.9 \pm 4.8 \%, P=$ N.S. $)$. There was no significant difference in age, gender, history of typical chest pain, time course to admission from onset of myocardial infarction, and coronary angiographic findings, such as the presence of multivessel disease and collateral circulation, between these two groups (Table 1). There was an association between patients with RI and a history of diabetes mellitus and smoking as compared to patients without RI, but there was no significant difference in the presence of any other risk factors between these two groups. The elevation of ST segment on ECG did not recover within 12 hours after coronary intervention in 20 of 32 patients $(62.5 \%)$ with RI as compared to in 9 of 35 patients $(25.7 \%)$ without RI $(P=0.0024)$.

\section{Coronary intervention}

Coronary intervention was performed using various devices as shown in Table 2. There was no significant difference in the methods of coronary intervention or the transient presence of slow flow or no reflow after coronary intervention between the patients with and without RI.

Stents were implanted in 27 patients with RI $(84.4 \%)$ and 25 patients without RI $(78.1 \%) \quad(P=$ N.S. $)$. When the type of stent was compared between the two groups, the diameters of the implanted stent and the dilated stent after ballooning were larger in the patients with RI than in the patients without RI $(P=0.0184$ and $P=0.0205)$, although there was no significant difference in the length of stents between the two groups.

When the lumen diameter before and after the procedure of coronary intervention (Table 3 ), and at 6 months follow-up were compared between 2 groups, the minimal lumen diameter after the procedure was significantly larger in the patients with $R I \quad(p=0.0316)$ than the patients without RI. 
Table 2. Lesion and procedure-related characteristics

\begin{tabular}{|c|c|c|c|}
\hline & 32 patients with $\mathrm{RI}$ & 35 patients without $\mathrm{RI}$ & $\mathrm{p}$ value \\
\hline Lesion location of LAD coronary artery & $\operatorname{seg} 6: 20 / \operatorname{seg} 7: 9 / \operatorname{seg} 8: 3$ & $\operatorname{seg} 6: 25 / \operatorname{seg} 7: 9 / \operatorname{seg} 8: 1$ & $p=$ N.S. \\
\hline Bifurcation & $11(34.3 \%)$ & $13(37.1 \%)$ & $p=$ N.S. \\
\hline Slow flow/no flow & $8(25.0)$ & $6(17.1)$ & $p=$ N.S. \\
\hline \multicolumn{4}{|l|}{ Strategies of coronary intervention } \\
\hline Balloon angioplasty & $1(3.1 \%)$ & $7(20.0 \%)$ & $p=\mathbf{N} . \mathbf{S}$. \\
\hline Ballooning and stenting & $21(65.6 \%)$ & $15(42.8 \%)$ & $p=$ N.S. \\
\hline Coronary atherectomy with TEC and ballooning & 0 & $2(5.7 \%)$ & $p=$ N.S. \\
\hline $\begin{array}{l}\text { Percutaneous thrombectomy with Rescue and } \\
\text { ballooning }\end{array}$ & $3(9.3 \%)$ & $2(5.7 \%)$ & $p=$ N.S. \\
\hline $\begin{array}{l}\text { Percutaneous thrombectomy with Rescue and } \\
\text { ballooning and stenting }\end{array}$ & $3(9.3 \%)$ & $2(5.7 \%)$ & $p=\mathbf{N} . \mathbf{S}$. \\
\hline $\begin{array}{l}\text { Percutaneous thrombectomy with Rescue and } \\
\text { stenting }\end{array}$ & $1(3.1 \%)$ & 0 & $p=$ N.S. \\
\hline IVCT and ballooning & $2(6.2 \%)$ & $2(5.7 \%)$ & $p=$ N.S. \\
\hline IVCT, ballooning and stenting & $1(3.1 \%)$ & $2(5.7 \%)$ & $p=$ N.S. \\
\hline $\begin{array}{l}\text { Direct coronary stenting without balloon } \\
\text { predilation }\end{array}$ & 0 & $2(5.7 \%)$ & $p=\mathbf{N} . \mathbf{S}$. \\
\hline Ballooning and stenting with distal protection & 0 & $1(2.8)$ & $p=$ N.S. \\
\hline Balloon size $(\mathrm{mm})$ with balloon angioplasty & $2.95 \pm 0.55 \mathrm{~mm}$ & $2.77 \pm 0.76 \mathrm{~mm}$ & $p=$ N.S. \\
\hline The diameter of stent size $(\mathrm{mm})$ & $3.27 \pm 0.34 \mathrm{~mm}$ & $3.05 \pm 0.33 \mathrm{~mm}$ & $p=0.0184$ \\
\hline The length of stent $(\mathrm{mm})$ & $17.1 \pm 4.53 \mathrm{~mm}$ & $16.7 \pm 5.46 \mathrm{~mm}$ & $p=$ N.S. \\
\hline Balloon and stent size $(\mathrm{mm})$ & $3.22 \pm 0.42 \mathrm{~mm}$ & $2.95 \pm 0.49 \mathrm{~mm}$ & $p=0.0205$ \\
\hline
\end{tabular}

LAD : left anterior descending coronary artery, TEC: transluminal extraction catheter device, Rescue : rescue aspiration catheter device, IVCT : intravenous coronary thrombolytic therapy, Distal protection : the protection of the microcirculation by balloon occlusion and aspiration system to prevent the distal embolization of thrombus or plaque material during balloon inflammation or stent deployment, $p=$ N.S : no significance. All data are expressed as the mean \pm 1 standard deviation.

Table 3. Quantitative angiographic findings

\begin{tabular}{lccc}
\hline & 32 patients with RI & 35 patients without RI & p value \\
\hline $\begin{array}{l}\text { Before procedure } \\
\text { Reference diameter (mm) }\end{array}$ & $2.51 \pm 0.48 \mathrm{~mm}$ & $2.29 \pm 0.42 \mathrm{~mm}$ & $p=$ N.S. \\
$\begin{array}{l}\text { Post procedure } \\
\text { Reference diameter (mm) }\end{array}$ & $2.68 \pm 0.52 \mathrm{~mm}$ & $p=$ N.S. \\
$\%$ diameter stenosis & $2.86 \pm 0.64 \mathrm{~mm}$ & $15.8 \pm 12.5 \%$ & $p=$ N.S. \\
Minimal lumen diameter (mm) & $14.4 \pm 8.1 \%$ & $1.96 \pm 0.47 \mathrm{~mm}$ & $p=0.0316$ \\
6 month follow up & $2.26 \pm 0.58 \mathrm{~mm}$ & & $p=$ N.S. \\
Reference diameter (mm) & $2.59 \pm 0.69 \mathrm{~mm}$ & $32.7 \pm 26.6 \%$ & $p=$ N.S. \\
$\%$ diameter stenosis & $35.4 \pm 28.7 \%$ & $1.56 \pm 0.64 \mathrm{~mm}$ & $p=$ N.S. \\
Minimal lumen diameter (mm) & $1.58 \pm 0.83 \mathrm{~mm}$ & 0 & $p=$ N.S. \\
Total occlusion & 0 & $7(25 \%)$ & $p=$ N.S. \\
Restenosis (diameter stenosis $>50 \%)$ & $7(30 \%)$ & & \\
\hline
\end{tabular}

$p=$ N.S.: no significance. All data are expressed as the mean \pm 1 standard deviation. 
Table 4. Left ventriculographic findings

\begin{tabular}{lccc}
\hline & 32 patients with RI & 35 patients without RI & p value \\
\hline Immediately after intervention & & \\
LVEF $(\%)$ & $38.4 \pm 11.7 \%$ & $43.9 \pm 9.7 \%$ & $p=$ N.S. \\
LVEDVi $\left(\mathrm{mL} / \mathrm{m}^{2}\right)$ & $95.2 \pm 39.8 \mathrm{~mL} / \mathrm{m}^{2}$ & $96.6 \pm 24.1 \mathrm{~mL} / \mathrm{m}^{2}$ & $p=$ N.S. \\
LVESVi $\left(\mathrm{mL} / \mathrm{m}^{2}\right)$ & $57.7 \pm 30.1 \mathrm{~mL} / \mathrm{m}^{2}$ & $54.5 \pm 15.8 \mathrm{~mL} / \mathrm{m}^{2}$ & $p=$ N.S. \\
6 months follow-up & & & \\
LVEF (\%) & $43.0 \pm 11.8 \%$ & $50.2 \pm 10.2 \%$ & $p=0.0259$ \\
LVEDVI ( \% change) & $101.0 \pm 27.2 \mathrm{~mL} / \mathrm{m}^{2}(-4.3 \pm 22.9 \%)$ & $85.2 \pm 24.1 \mathrm{~mL} / \mathrm{m}^{2}(+11.1 \pm 22.5 \%)$ & $p=0.0343(\mathrm{p}=0.0273)$ \\
LVESVI (\% change) & $59.6 \pm 25.8 \mathrm{~mL} / \mathrm{m}^{2}(-4.3 \pm 39.2 \%)$ & $42.6 \pm 15.6 \mathrm{~mL} / \mathrm{m}^{2}(+20.8 \pm 23.3 \%)$ & $p=0.006(\mathrm{p}=0.01)$ \\
\hline
\end{tabular}

LVEF : left ventricular ejection fraction, LVEDVi : left ventricular end-diastolic volume index, LVESVi : left ventricular end-diastolic volume index. $p=$ N.S.: no significance. All data are expressed as the mean \pm 1 standard deviation.

\section{Left ventricular function and dilatation}

Left ventricular function was compared between the patients with and without RI (Table

4) There was no significant difference immediately after the procedure $(38.4 \pm 11.7 \%$ versus $43.9 \pm 9.7 \%, P=$ N.S.), although at the 6-month follow-up after coronary intervention, the LVEF was lower in the patients with RI than the patients without RI $(43 \pm 11.8 \%$ versus $50.2 \pm 10.2 \%, P=0.0259)$. The left ventricular volume after 6 months was larger in the patients with RI as compared to the patients without RI (LVEDVi : $101.0 \pm 27.2 \mathrm{~mL} / \mathrm{m} 2$ versus $85.2 \pm 24.1 \mathrm{~mL} / \mathrm{m} 2, P=0.0343,-4.3 \pm 22.9 \%$ versus $+11.1 \pm 22.5 \%, P=0.0273$, LVESVi : $59.6 \pm 25.8 \mathrm{~mL} / \mathrm{m} 2$ versus $42.6 \pm 15.6 \mathrm{~mL} / \mathrm{m} 2, P=0.006,-4.3 \pm 39.2 \%$, versus $+20.8 \pm 23.3 \%, \quad P=0.01)$, although no significant difference in LVED was found immediately after the procedure (LVEDVi : $95.2 \pm 39.8 \mathrm{~mL} / \mathrm{m} 2$ versus $96.6 \pm 24.1 \mathrm{~mL} / \mathrm{m} 2$, $P=$ N.S., LVESVi: $57.7 \pm 30.1 \mathrm{~mL} / \mathrm{m} 2$ versus $54.5 \pm 15.8 \mathrm{~mL} / \mathrm{m} 2, P=$ N.S. ).

\section{Discussion}

Following up on early experimental findings ${ }^{17,18)}$, recent clinical observation has confirmed the existence of microvascular reperfusion injury after successful coronary intervention ${ }^{19,20)}$. Myocardial contrast echocardiogram ${ }^{5)}$ and contrast-enhanced MRI $^{6)}$ were used clinically to detect the RI. However, these methods can only provide a qualitative evaluation of the reperfusion injury, according to the presence of contrast defect or the grade of enhancement in the risk area compared to successful myocardial perfusion. The position or the extent of the infarct or risk area is evaluated only by myocardial perfusion. In the clinical setting, thallium-201 SPECT imaging is now used widely to quantitatively evaluate the severity of myocardial perfusion ${ }^{21)}$. Furthermore, a quantitative estimation of infarct size can be provided using Tc-pyrophosphate imaging ${ }^{11)}$ or/and thallium-201 imaging ${ }^{10)}$.

In the present study, we first detected the infarct-related region quantitatively using Tc-pyrophosphate SPECT images. Second, we measured the myocardial perfusion flow quantitatively in the infarct-related region after successful coronary intervention. Finally, we assessed that the existence of RI on the basis of overlap images was associated with a poor prognosis, which is correlated to factors such as larger infarct size, poor recovery of left ventricular function, and the presence of left ventricular dilatation despite successful 
coronary intervention of TIMI grade 3 within the optimal time ${ }^{22}$ after acute myocardial infarction.

Our prognostic results support previous studies on patients with microvascular RI, which was detected using myocardial contrast echocardiogram, contrast-enhanced MRI, and doppler guide wire into the intra-coronary, in terms of the large infarct size, the reduced left ventricular function and the left ventricular remodeling ${ }^{5,6)}$. Furthermore, other reports have cited the persistent ST-segment elevation early after angioplasty as a marker of poor prognosis with $\mathrm{RI}^{7)}$. The preservation of ST-segment elevation more than 12 hours after successful coronary intervention in our patients with RI supports our hypothesis. The mechanism or the time course of microvascular RI in infarct-related myocardium remains unclear. When the reperfusion occurs and blood flow to the infarct region is restored, the microvascular RI is caused by factors such as neutrophil infiltration and generation of oxygen free radicals ${ }^{23)}$. Damaged myocytes and arterioles are thought to prevent the microvascular perfusion flow by increasing distal vascular resistance and by stimulating arteriolar spasm. In addition, platelet micro-emboli are thought to move down the vessels after plaque rupture ${ }^{24}$. Thus, microvascular dysfunction may be caused by the complex and sequential participation of many factors ${ }^{25)}$. The microvascular damage caused by these mechanisms may be reversible after coronary reflow ${ }^{26)}$. Accordingly, RI must be detected early after coronary intervention following acute myocardial infarction. Experimental studies have documented transient and progressive microvascular damage up to 3.5 hours after reperfusion ${ }^{27)}$. However, the recent study using contrast-enhanced MRI documented progressive microvascular obstruction within an infarct-related region up to 48 hours after coronary reflow ${ }^{28)}$. In the present study, the existence of microvascular RI was evaluated accurately because the overlap images with dual-isotope SPECT were obtained at 48 hours after coronary intervention.

In the present study, the presence of reperfusion injury was defined as $\leq 60 \%$ uptake of thallium-201 in the infarct-related region, as estimated by Tc-pyrophosphate imaging. On the other hand, the \% uptake of thallium-201 in the defined infarct-related region was correlated to the left ventricular function in the chronic phase $(r=0.53, P=0.027)$. Thus, we propose from the quantitative analysis that the severity of microvascular RI is correlated to patient prognosis, although the small sample size used here prevents a more close correlation.

\section{Study limitation}

There were significant differences in some parameters between the patients with and without RI in this study, and these parameters may also have influenced patient prognosis. First, the RI rate was weakly related to the history of diabetes mellitus or smoking. Although the magnitude of RI may be associated with risk factors of cardiovascular function such as smoking, hypertension, hyperlipidemia, and diabetes mellitus ${ }^{29)}$, previous studies indicate that the duration of ischemia and/or time to recanalization are the most powerful determinants of microvascular dysfunction ${ }^{26)}$. Second, the minimal lumen diameter immediately after the procedure was larger in the patients with RI than in those without RI. However, in both groups, the minimal lumen diameter was less than $2 \mathrm{~mm}$, and the \% diameter stenosis was less than $20 \%$. We are convinced that this result is not related to the degree of microvascular reperfusion flow, because the difference in luminal diameter did not 
influence microvascular perfusion in the previous study ${ }^{30)}$.

\section{In conclusion}

The existence of microvascular reperfusion injury after acute myocardial infarction can determine a poor prognosis, despite successful coronary intervention of TIMI grade III immediately after acute myocardial infarction. The RI was quantitatively detected and analyzed using overlap SPECT images of Tc-PYP/thallium-201 taken 48 hours after reperfusion.

\section{Acknowledgments}

We thank Masashi Akiyama for technical assistance in performing this study. We also thank Mikitaka Murakami, MD, Hiroki Takenaka, MD, and Tien-Yin Huang, MD, for their close cooperation.

\section{References}

1) Grines CL, Browne KF, Marco J, Rothbaum D, Stone GW, O'Keefe J, Overlie P, Donohue B, Chelliah N, Timmis GC, Vlietstra RE, Strzelecki M, Puchrowicz-Ochocki S and O’Neill WW, for The Primary Angioplasty in Myocardial Infarction Study Group: A comparison of immediate angioplasty with thrombolytic therapy for acute myocardial infarction. The Primary Angioplasty in Myocardial Infarction Study Group. $N$ Engl J Med 328 : 673-679 (1993)

2) Gibson CM, Cannon CP, Daley WL, Dodge JT Jr, Alexander B Jr, Marble SJ, McCabe CH, Raymond L, Fortin T, Poole WK and Braunwald E: TIMI frame count: a quantitative method of assessing coronary artery flow. Circulation $93: 879-888$ (1996)

3) Edep ME, Guarneri EM, Teirstein PS, Phillips PS and Brown DL : Differences in TIMI frame count following successful reperfusion with stenting or percutaneous transluminal coronary angioplasty for acute myocardial infarction. Am J Cardiol 83 : 1326-1329 (1999)

4) Kenner MD, Zajac EJ, Kondos GT, Dave R, Winkelmann JW, Joftus J, Laucevicius A, Kybarskis A, Berukstis E, Urbonas A and Feinstein SB : Ability of the no-reflow phenomenon during an acute myocardial infarction to predict left ventricular dysfunction at one-month follow-up. Am J Cardiol $76: 861-868$ (1995)

5) Ito H, Maruyama A, Iwakura K, Takiuchi S, Masuyama T, Hori M, Higashino Y, Fujii K and Minamino T: Clinical implications of the 'no reflow' phenomenon. A predictor of complications and left ventricular remodeling in reperfused anterior wall myocardial infarction. Circulation 93 : 223-228 (1996)

6) Wu KC, Zerhouni EA, Judd RM, Lugo-Olivieri CH, Barouch LA, Schulman SP, Blumenthal RS and Lima JA : Prognostic significance of microvascular obstruction by magnetic resonance imaging in patients with acute myocardial infarction. Circulation 97 : 765-772 (1998)

7) Claeys MJ, Bosmans J, Veenstra L, Jorens P, De Raedt H and Vrints CJ : Determinants and prognostic implications of persistent ST-segment elevation after primary angioplasty for acute myocardial infarction: importance of microvascular reperfusion injury on clinical outcome. Circulation 99 : 1972-1977 (1999)

8) Garot J, Scherrer-Crosbie M, Monin JL, DuPouy P, Bourachot ML, Teiger E, Rosso J, Castaigne A, Gueret $P$ and Dubois-Rande : Effect of delayed percutaneous transluminal coronary angioplasty of occluded coronary arteries after acute myocardial infarction. Am J Cardiol 77 : 915-921 (1996)

9) Watanabe J, Nakamura S, Sugiura T, Takehana K, Hamada S, Miyoshi H, Saito D, Hatada K, Kurihara H, Baden $\mathbf{M}$ and Iwasaka $\mathbf{T}$ : Early identification of impaired myocardial reperfusion with serial assessment of ST segments after percutaneous transluminal coronary angioplasty during acute myocardial infarction. Am $J$ Cardiol 88 : 956-959 (2001)

10) Jansen DE, Corbett JR, Wolfe CL, Lewis SE, Gabliani G, Filipchuk N, Redish G, Parkey RW, Buja LM, Jaffe AS, Rude R, Sobel BE and Willerson JT: Quantification of myocardial infarction: a comparison of single photon-emission computed tomography with pyrophosphate to serial plasma MB-creatine kinase measurements. Circulation 72 : 327-333 (1985)

11) Kawaguchi K, Sone T, Tsuboi H, Sassa H, Okumura K, Hashimoto H, Ito T and Satake T: Quantitative estimation of infarct size by simultaneous dual radionuclide single photon emission computed tomography: comparison with peak serum creatine kinase activity. Am Heart J 121 : 1353-1360 (1991)

12) Asano H, Sone T, Tsuboi H, Sassa H, Takeshima K, Miyazaki Y, Okumura K, Hashimoto $H$ and Ito T: Diagnosis of right ventricular infarction by overlap images of simultaneous dual emission computed tomography using technetium-99m pyrophosphate and thallium-201. Am J Cardiol 71:902-908 (1993) 
13) Umezawa S, Obayashi T, Chun YH, Adachi H, Kanayama $M$, Korenaga $M$, Inada $\mathbf{M}$ and Taniguchi $\mathbf{K}$ : Clinical significance of the technetium- $99 \mathrm{~m} /$ thallium-201 overlap in acute myocardial infarction. $J$ Cardiol 19 : 981-990 (1989)

14) Austen WG, Edwards JE, Frye RL, Gensini GG, Gott VL, Griffith LS, McGoon DC, Murphy ML and Roe BB : A reporting system on patients evaluated for coronary artery disease. Report of the Ad Hoc Committee for Grading of Coronary Artery Disease, Council on Cardiovascular Surgery, American Heart Association. Circulation 51 : 5-40 (1975)

15) Rentrop KP, Cohen M, Blanke $\mathbf{H}$ and Philips RA : Changes in collateral channel filling immediately after controlled coronary artery occlusion by an angioplasty balloon in human subjects. J Am Coll Cardiol 5 : 587-592 (1985)

16) Snadler $\mathrm{H}$ and Dodge HT: The use of single plane angiograms for the calculation of left ventricular volume in man. Am Heart $J$ $75: 325-334$ (1968)

17) Kloner RA, Ganote CE and Jennings RB: The "no-reflow" phenomenon after temporary coronary occlusion in the dog. $J$ Clin Invest $54: 1496-1508$ (1974)

18) Kloner RA, Rude RE, Carlson N, Maroko PR, DeBoer LW and Braunwald E: Ultrastructural evidence of microvascular damage and myocardial cell injury after coronary artery occlusion: which comes first? Circulation 62 : 945-952 (1980)

19) Ito H, Tomooka T, Sakai N, Yu H, Higashino Y, Fujii K, Masuyama T, Kitabatake A and Minamino T: Lack of myocardial perfusion immediately after successful thrombolysis. A predictor of poor recovery of left ventricular function in anterior myocardial infarction. Circulation $85: 1699-1705$ (1992)

20) Lincoff AM and Topol EJ : Illusion of reperfusion. Does anyone achieve optimal reperfusion during acute myocardial infarction? Circulation 88 : 1361-1374 (1993)

21) Ficaro EP and Corbett JR : Advances in quantitative perfusion SPECT imaging. $J$ Nucl Cardiol 11:62-70 (2004)

22) Ellis SG, O'Neill WW, Bates ER, Walton JA Jr, Nabel EG, Werns SW and Topol EJ : Implications for patient triage from survival and left ventricular functional recovery analyses in 500 patients treated with coronary angioplasty for acute myocardial infarction. J Am Coll Cardiol 13 : 1251-1259 (1989)

23) Maxwell SR and Lip GY : Reperfusion injury: a review of the pathophysiology, clinical manifestations and therapeutic options. Int J Cardiol 58 : 95-117 (1997)

24) Topol EJ and Yadav JS : Recognition of the importance of embolization in atherosclerotic vascular disease. Circulation 101 : 570-580 (2000)

25) Roe MT, Ohman EM, Maas AC, Christenson RH, Mahaffey KW, Granger CB, Harrington RA, Califf RM and Krucoff MW: Shifting the open-artery hypothesis downstream: the quest for optimal reperfusion. $J A m$ Coll Cardiol 37 : 9-18 (2001)

26) Agati L : Microvascular integrity after reperfusion therapy. Am Heart J 138 : S76-S78 (1999)

27) Ambrosio G, Weisman HF, Mannisi JA and Becker LC: Progressive impairment of regional myocardial perfusion after initial restoration of postischemic blood flow. Circulation 80 : 1846-1861 (1989)

28) Rochitte CE, Lima JA, Bluemke DA, Reeder SB, McVeigh ER, Furuta T, Becker LC and Melin JA: Magnitude and time course of microvascular obstruction and tissue injury after acute myocardial infarction. Circulation 98 : 1006-1014 (1998)

29) Granger DN : Ischemia-reperfusion: mechanisms of microvascular dysfunction and the influence of risk factors for cardiovascular disease. Microcirculation $6: 167-178$ (1999)

30) Kern MJ, Dupouy P, Drury JH, Aguirre FV, Aptecar E, Bach RG, Caracciolo EA, Donohue TJ, Rande JL, Geschwind HJ, Mechem CJ, Kane G, Teiger E and Wolford TL : Role of coronary artery lumen enlargement in improving coronary blood flow after balloon angioplasty and stenting: a combined intravascular ultrasound Doppler flow and imaging study. J Am Coll Cardiol 29 : 1520-1527 (1997)

[Received January 19, 2004 : Accepted February 13, 2004] 